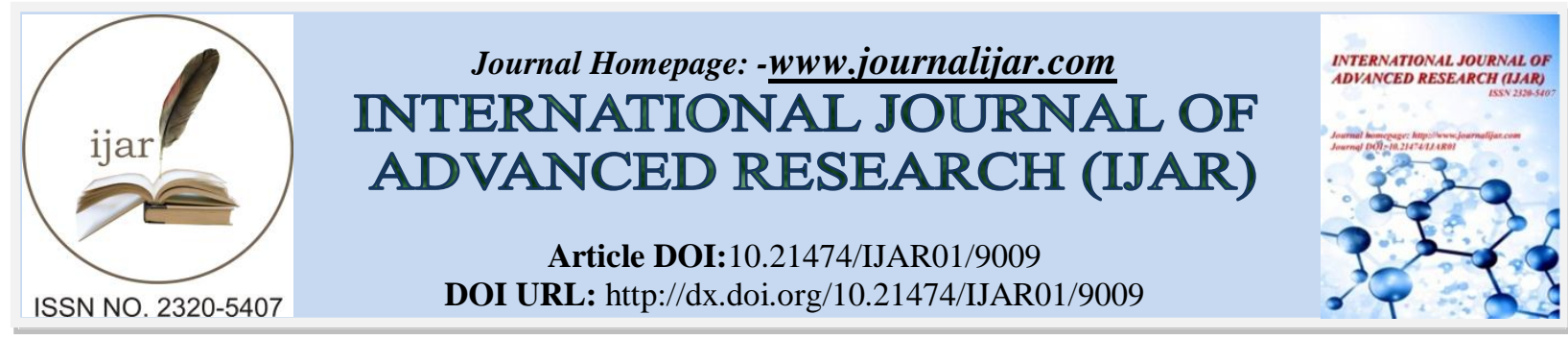

RESEARCH ARTICLE

\title{
EFFECT OF PNEUMOPERITONIUM WITH CARBON DIOXIDE IN ABDOMINAL LAPAROSCOPIC SURGERIES ON HEMODYNAMIC AND ARTERIAL BLOOD GAS PARAMETERS.
}

Naqeeb Hassan, Rohey Jan, Abdul Qayoom Loneand Syed AmerZahoor.

Department of Anesthesiology and Critical Care, Sheri - Kashmir Institute of Medical Sciences, Soura - Srinagar, Jammu and Kashmir, India .

\section{Manuscript Info}

\section{Manuscript History}

Received: 02 March 2019

Final Accepted: 04 April 2019

Published: May 2019

Key words:-

Co2 Pneumoperitoneum, ASA status,

$\mathrm{PaCo} 2, \mathrm{EtCo} 2$.

\section{Abstract}

Introduction:During laparoscopy, pneumoperitoneum is essential to provide a good surgical field, allowing visibility and performance of surgical maneuvers. Carbon dioxide is the most commonly used gas for pneumoperitoneum.

AIMS \&Objectives : (1). To determine the hemodynamic changes due to $\mathrm{Co} 2$ Pneumoperitonium during laparoscopic surgery, (2). Correlation between $\mathrm{PaCo} 2$ and $\mathrm{EtCo} 2$ (3) Metabolic effects of $\mathrm{Co} 2$ pneumoperitonium and (4). To identify high risk groups to laparoscopic surgery due to $\mathrm{Co} 2$ Pneumoperitonium.

Material \& Methods : This observational study was conducted in the Department of Anaesthesiology and Critical Care, SKIMS Srinagar - Kashmir ,which is a tertiary care referral centre over a period of one year, after obtaining approval from institutional ethical committee and consent of the patients. The sample size of 100 patients, above 18 years of age after fullfilling inclusion \& exclusion criteria were enrolled for the study .

Result :There were female prepondance, with 67 Females \& 33 were Male. Majority of the patients were in the age group of $45-59$ years, with Mean age of 43.1 years .On comparing theASA Physical status of study patients, majority were in ASA I = 34 patients , followed by ASA II = 32, ASA III \& ASA IV = 17 each . Majority of patients $(58 \%)$, underwent LAP Cholecystectomy. In our study we found that, there was gradual decrease in PH over time during the procedure. The change in $\mathrm{PH}$ was significant (p-value $<0.05$ ) with mean $\mathrm{PH}$ of 7.41 in preoperative period, which decreased to $\mathrm{PH}$ 7.28 at 180 minutes. However there was increase in $\mathrm{pH}$ in postoperative period with mean $\mathrm{pH}$ 7.32. we also found that $\mathrm{PaCO}_{2}$ increased significantly after $\mathrm{Co}_{2}$ Pneumoperitonium , with mean $\mathrm{PaCO}_{2}$ of $35.0 \mathrm{mmHg}$ in preoperative period and $\mathrm{PaCO}_{2}$ of $47 \mathrm{mmHg}$ at 180 minutes. After deflation and extubation $\mathrm{PaCO}_{2}$ decreased in the postop with mean value of $39.4 \mathrm{mmHg}$.we found significant ( $\mathrm{p}$-value $=<0.05$ ) increase in $\mathrm{PaCO}_{2}$ during the procedure and it remained on higher side after extubation. There was significant increase in End tidal $\mathrm{Co} 2($ $\mathrm{EtCo}_{2}$ ) after $\mathrm{Co}_{2}$ insufflation with, mean $\mathrm{EtCO}_{2}=31.0 \mathrm{mmHg}$ before insufflation, which increased to mean value of $39.8 \mathrm{mmHg}$ at 
$90 \min (\mathrm{p}$-value $<0.05)$. There was significant change in Minute ventilation, before $\mathrm{Co} 2$ insufflation was $5.028 \mathrm{~L} / \mathrm{min}$, which increased to a maximum mean value of $8.4 \mathrm{~L} / \mathrm{min}$ at $180 \mathrm{~min}$ ( $\mathrm{P}$ value Significant ). Mean $\mathrm{HCo}_{3}$ was $24.9 \mathrm{mEq} / \mathrm{L}$ which decreased to mean value of $21.8 \mathrm{mEq} / \mathrm{L}$ at $15 \mathrm{~min}$. After $15 \mathrm{~min}$ there was satatiscally no significant change in bicarbonate levels. There was no significant mean difference between $\mathrm{PaCo}_{2}-\mathrm{EtCo}_{2}$ over time during the procedure . Compared to baseline $\mathrm{H} / \mathrm{R}$ (mean $\mathrm{HR}=78.5 \mathrm{~b} / \mathrm{min}$ ), there was significant increase in $\mathrm{H} / \mathrm{R}$ after induction of anesthesia and PNP (mean $\mathrm{HR}=107.8 \mathrm{~b} / \mathrm{min}$ ) which remained significantly raised up to $60 \mathrm{~min}$ of the procedure . we also found that, there was significant rise in $H / R$ after extubation (mean $H R=92.7$ beats/min). The changes in MAP, which corresponds to change in SBP \& DBP were studied in relation to baseline value (mean preoperative $\mathrm{MAP}=96.9 \mathrm{mmHg}$ ), There was significant decrease in MAP $(90.2+6.3 \mathrm{mmHg})$ after induction, followed by significant rise in MAP up to first $45 \mathrm{~min}$, thereafter there was no significant change in MAP.

Conclusion :In our study, we concluded that laparoscopic surgery with $\mathrm{Co} 2$ pneumoperitonium lead to significant acidosis, increase in $\mathrm{PaCo} 2$ and decrease in bicarbonate levels, as well as there was a significant change in hemodynamic parameters. These changes were well tolerated by patients by optimizing patients prior to surgery. A correlation was observed between the $\mathrm{PaCo} 2$ and $\mathrm{EtCo} 2$ throughout the duration of the insufflation making $\mathrm{EtCo} 2$ a reliable monitor of $\mathrm{Co} 2$ output during laparoscopy. we also noted significant rise in H/R , BP \& MAP, but these changes were well tolerated by patients belonging to different ASA categories. In our study high risk patients (ASA II, III, and IV) were optimized before surgery and the changes induced during procedure were well compensated.

Copy Right, IJAR, 2019,. All rights reserved.

\section{Introduction:-}

Laparoscopic surgery is nowadays a common daily-performed procedure worldwide, replacing many types of open surgeries. It has the benefits of small incision, improved cosmetic aspects, less postoperative pain, and quick recovery time to normal activities $[1,2] . \mathrm{CO} 2$ is an ideal gas for pneumoperitoneum secondary to its low combustibility and high blood solubility, which decreases the risk of gas embolism [3-7].Pneumoperitoneum can induce many pathophysiologic disturbances like increases mean arterial pressure (MAP) and systemic vascular resistance (SVR) and may decrease cardiac output CO. [8 ], requiring the anesthesiologist to be well alert during the operation for necessary management. Moreover, advanced laparoscopic surgeries are being used also on older patients and in critically ill patients, requiring technically demanding anesthesia .

\section{Aims \& Objectives:-}

(1). To determine the hemodynamic changes due to Co2Pneumoperitonium during laparoscopic surgery, (2). To determine the correlation between PaCO2 and EtCO2 during Laproscopic surgery, (3).To determine the metabolic effects of $\mathrm{CO} 2$ pneumoperitonium during laparoscopic surgery, (4).To identify high risk groups to laparoscopic surgery due to $\mathrm{CO} 2$ pneumoperitonium.

\section{Material \& Methods:-}

An observational study was conducted on 100 patients above 18 years of age posted for laparoscopic surgeries , after obtaining approval from institutional ethical committee and consent of the patients. This study was conducted in the Postgraduate Department of Anaesthesiology and Critical Care Sher-i-Kashmir Institute of Medical Sciences Soura-Srinagar, Kashmir. 
Inclusion criteria was (1) Patients above age of consent i.e. 18 years undergoing laparoscopic surgeries .Exclusion criteriawere (1) . patients refusal (2). Patients for emergency laparoscopy(3). Patients who were converted to an open procedure.

\section{Methodology:-}

In the pre-operative assessment, the patients were enquired about any comorbid disease, history of drug allergy, previous operations, loose teeth and artificial dentures or prolonged drug treatment. General examination, systemic examinations, and assessment of the airway was done. Preoperative fasting of minimum 8 hours was ensured before operation in all cases. All patients were clinically examined in the preoperative period, where whole procedure was explained and written consent obtained. All patients were investigated for CBC, KFT, LFT, ECG and chest X-ray. On entering the patient in the operative room, standard monitors like ECG, pulse oximeter, noninvasive blood pressure were attached and baseline parameters were recorded. Intravenous line was secured with $18 \mathrm{G}$ cannula thereafter surgery was Performed by standard procedure under general anaesthesia.

Pre-oxygenation with $100 \%$ oxygen was done for three minutes with face mask. Induction was done by administering propofol ( $2 \mathrm{mg} / \mathrm{kg}$ body weight), fentany $2 \mathrm{mcg} / \mathrm{kg} \mathrm{IV}$, muscle relaxation was provided by injection atracurium $(0.5 \mathrm{mg} / \mathrm{kg}$ body weight loading dose and maintenance dose of $0.1 \mathrm{mg} / \mathrm{kg}$ as per the requirement) and then patient was intubated with endotracheal tube of the appropriate size. Inhalation of isoflurane as per the MAC was used for maintenance of anesthesia. Patients were ventilated with tidal volume of 6-8 ml/kg and respiratory rate adjusted to maintain EtCO2 within 35 to $45 \mathrm{mmHg}$ or haemodynamic changes attributable to elevated Co2 . End tidal $\mathrm{C} 02, \mathrm{PaCo} 2, \mathrm{pH}$, and Bicarbonate measurement was done before, and after $\mathrm{Co} 2$ pneumoperitoneum and analysed.

Arterial blood samples were taken at regular intervals depending upon duration of surgery e.g. First sample was taken before Co2 pneumoperitonium, Second sample was taken 15min after Co2 pneumoperitoneum, third sample after 30 mins, subsequent sampling was done at regular intervals depending on duration of surgery and last sample was collected after the patient was extubated and ascertained to be adequately breathing spontaneously. The EtCo2 at the time of sampling was recorded. Hemodynamic parameters Heart rate (HR), Blood pressure (BP), Mean arterial pressure (MAP), ECG Changes was recorded before induction, immediately before creation of pneumoperitonium after pneumoperitonium and thereafter every 15minutes, and last reading was taken after extubation. The above said parameters were recorded and patients were further sub- categorised in to low risk, moderate risk and high risk groups depending upon severity of derangements in hemodynamic and metabolic parameters obtained, as well as on the basis of patient characteristics, associated comorbidity and duration of surgery.

Correlation between EtCo2 and $\mathrm{PaCo} 2$, hemodynamic parameters, patient characteristics, co-morbidity and duration of surgery was evaluated statistically and inferences drawn based on the statistical data obtained.

\section{Result \& Observations:-}

This observational study was conducted at Sher-i-Kashmir Institute of Medical Sciences Soura, over a period of one year. In this study, 100 patients undergoing for laparoscopic surgery under general anesthesia were studied for effects of carbon dioxide pneumoperitonium on hemodynamics and arterial blood gas parameters.

Table 1 : -Gender distribution of study patients

\begin{tabular}{|l|l|l|}
\hline Gender & Frequency & Percentage \\
\hline Male & 33 & $33 \%$ \\
\hline Female & 67 & $67 \%$ \\
\hline Total & 100 & \\
\hline
\end{tabular}

Table 2:-Age distribution of study patients

\begin{tabular}{|l|l|l|}
\hline \hline Age (years) & Frequency & Percentage \\
\hline $15-29$ & 25 & $25 \%$ \\
\hline $30-44$ & 24 & $24 \%$ \\
\hline $45-59$ & 29 & $29 \%$ \\
\hline
\end{tabular}




\begin{tabular}{|l|l|l|}
\hline$\geq 60$ & 22 & $22 \%$ \\
\hline Mean $\pm \mathrm{SD}=43.1 \pm 16.12$ & \\
\hline
\end{tabular}

Table 3:-ASA status of study patients

\begin{tabular}{|l|l|l|}
\hline \hline ASA Status & Frequency & Percentage \\
\hline ASA I & 34 & $34 \%$ \\
\hline ASA II & 32 & $32 \%$ \\
\hline ASA III & 17 & $17 \%$ \\
\hline ASA IV & 17 & $17 \%$ \\
\hline Total & 100 & $100 \%$ \\
\hline
\end{tabular}

Table 4 :-Distribution of study patient as per surgical procedure

\begin{tabular}{|l|l|l|}
\hline Surgical Procedure & Frequency & Percentage \\
\hline Diagnostic LAP & 17 & $17 \%$ \\
\hline LAP Adrenalectomy & 7 & $7 \%$ \\
\hline LAP Cholecystectomy & 58 & $58 \%$ \\
\hline LAP Spleenectomy & 8 & $8 \%$ \\
\hline LAP Gastrectomy & 3 & $3 \%$ \\
\hline LAP Orhidectomy & 2 & $2 \%$ \\
\hline LAP Enucleation & 3 & $3 \%$ \\
\hline LAP Excision & 1 & $1 \%$ \\
\hline LAP TAH BSO & 1 & $1 \%$ \\
\hline Total & 100 & $100 \%$ \\
\hline
\end{tabular}

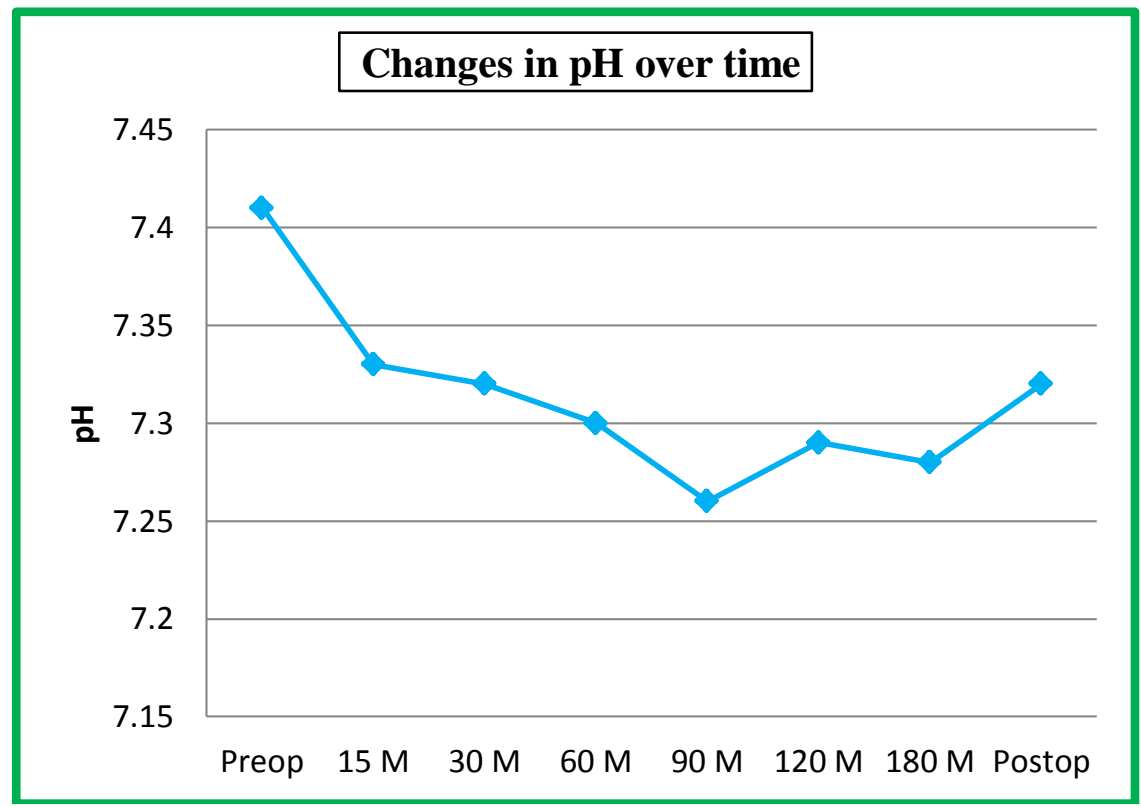

Figure 5:-Line chart showing changes in $\mathrm{pH}$ over time. 


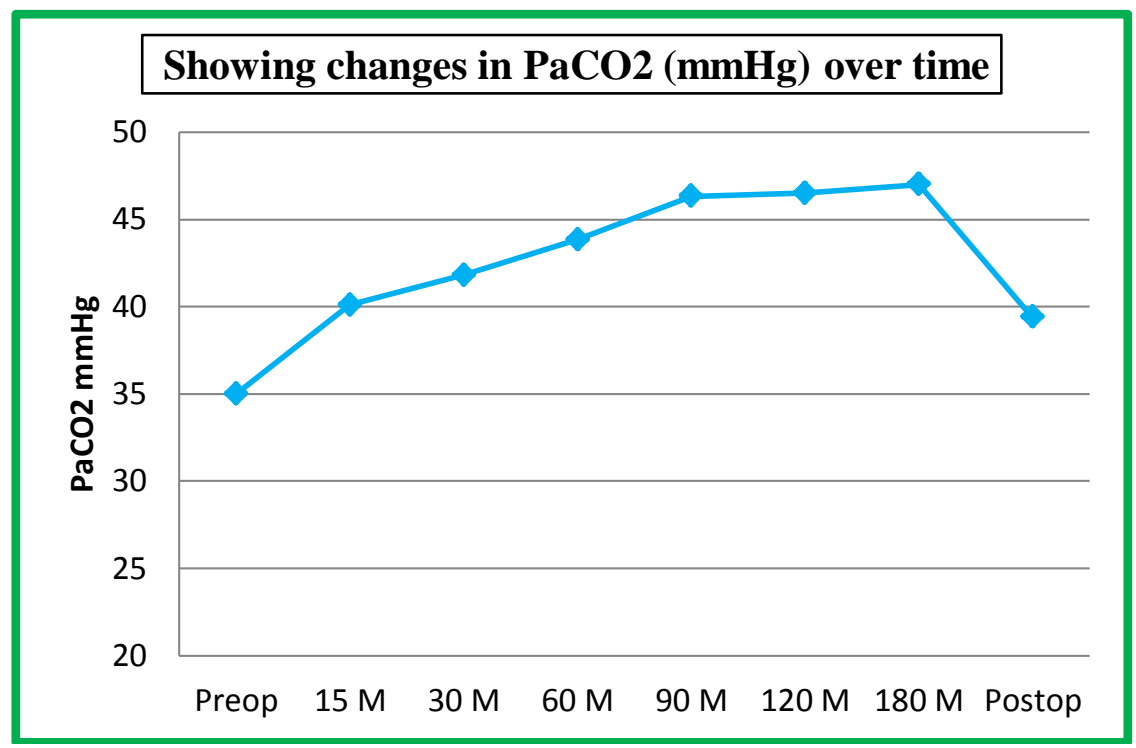

Figure 6:-Line chart showing changes in $\mathrm{PaCO}_{2}$ over a period of time.

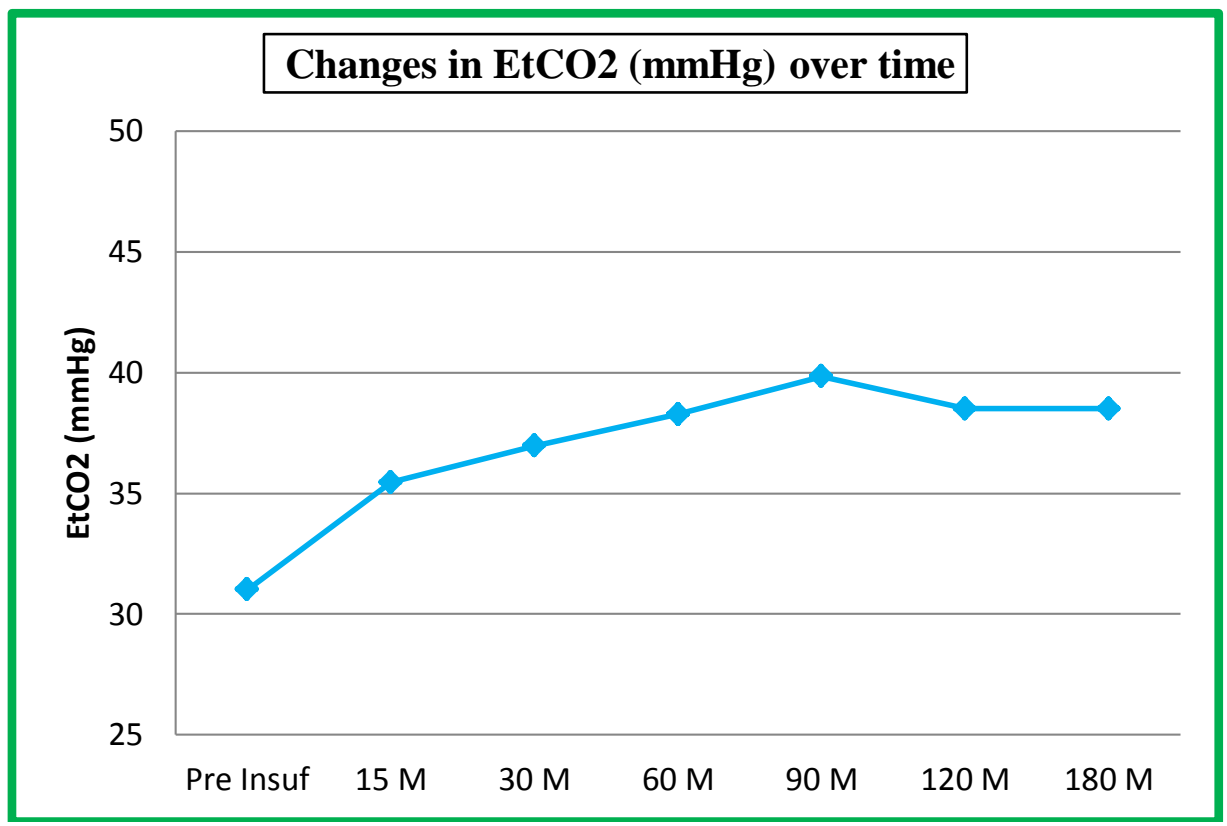

Figure 7:-Line chartshowing changes in $\mathrm{EtCO} 2(\mathrm{mmHg})$ over time . 


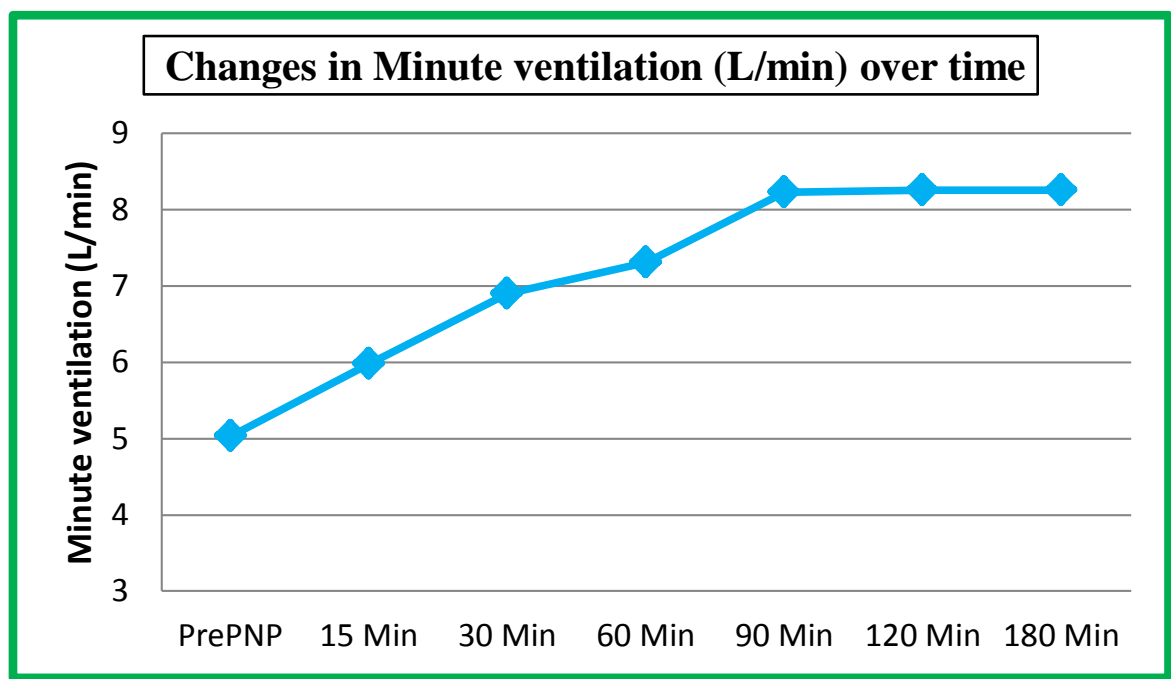

Figure 8:-Line chart showing changes in Minute ventilation (L/min) over time .

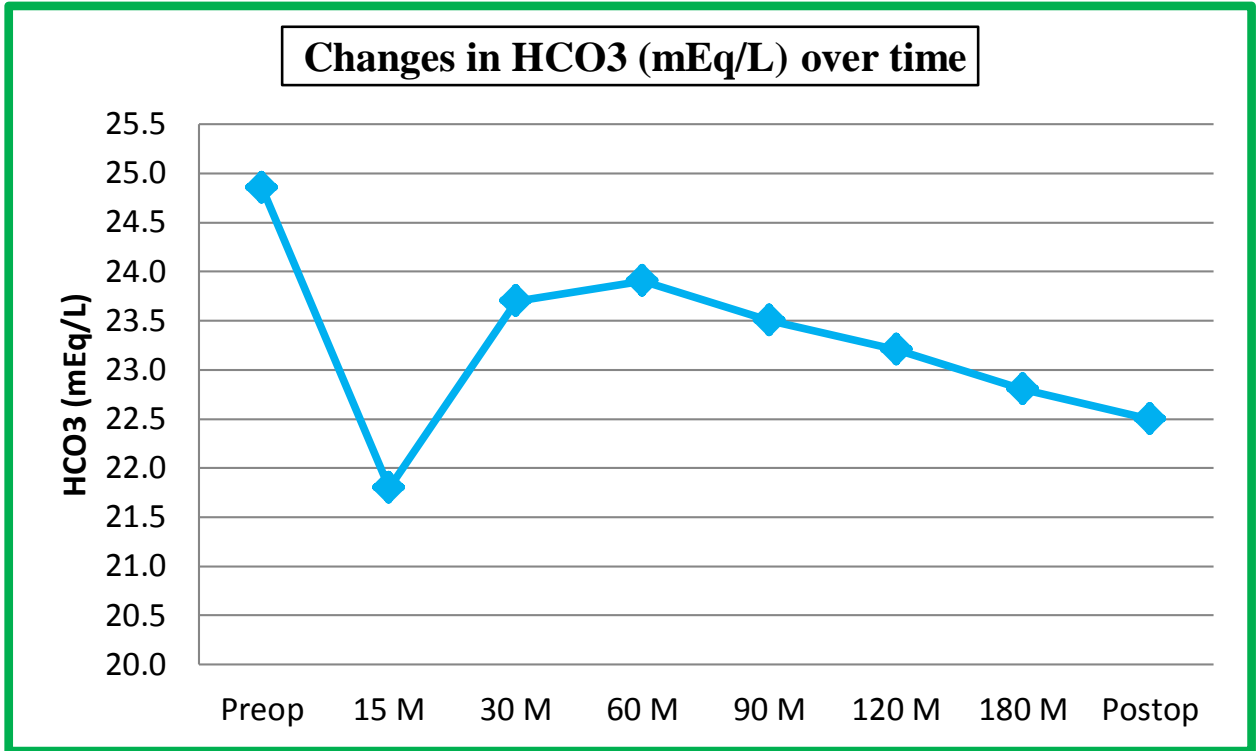

Figure 9:-Line chart showing changes in $\mathrm{HCO}_{3}$ over time

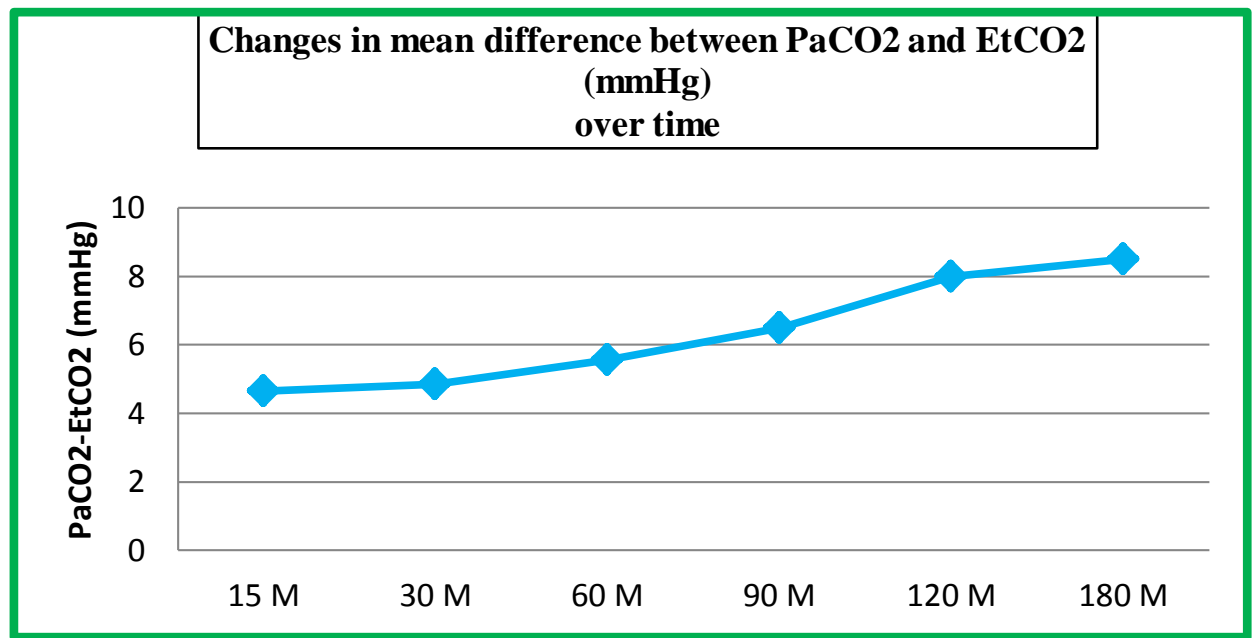

Figure 10:-Line chart showing changes in $\mathrm{PaCO}_{2}$-EtCO2 over time 


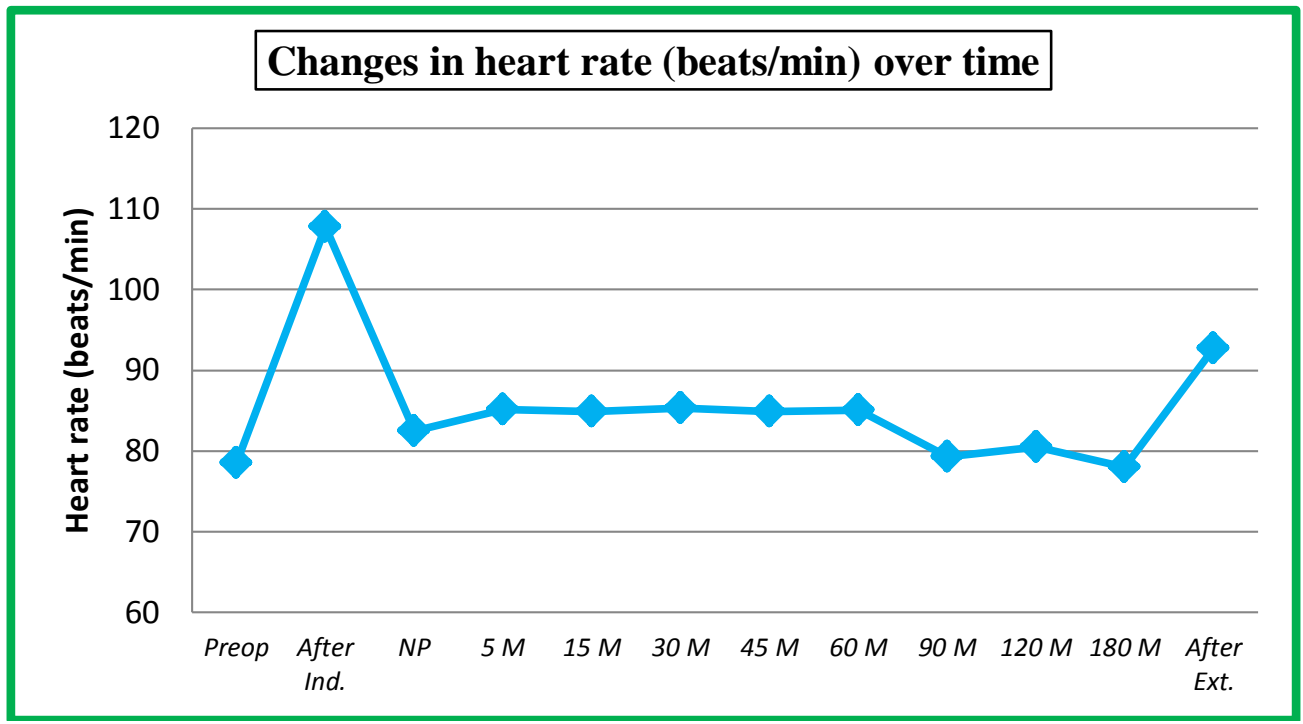

Figure 11:-Line chartshowing changes in Heart rate over time

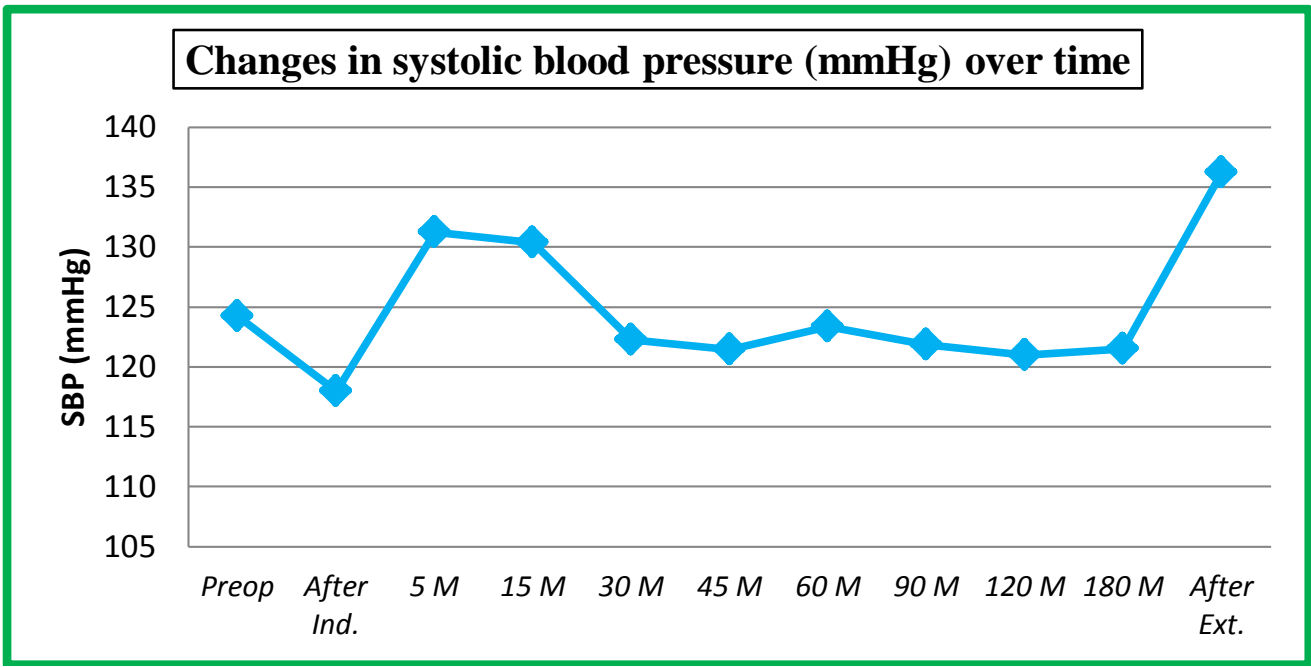

Figure 12:-Line chartshowing changes in systolic blood-pressure (SBP) over time.

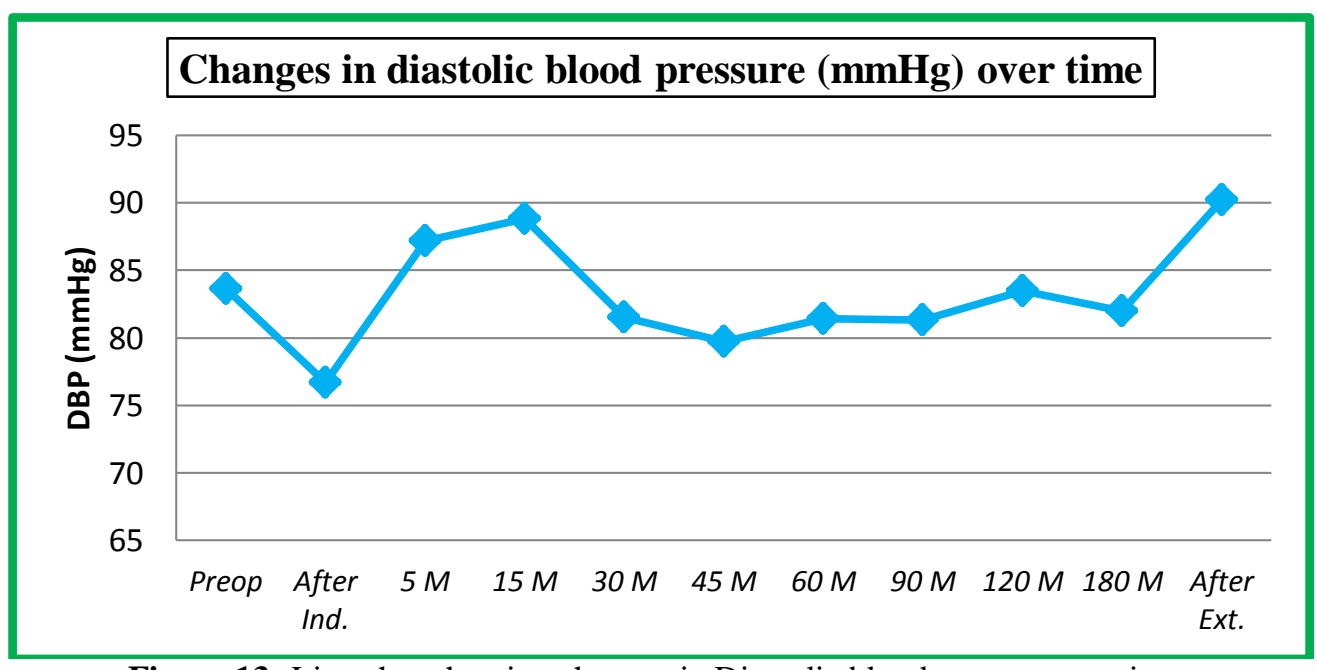

Figure 13:-Line chartshowing changes in Diastolic blood presure over time. 


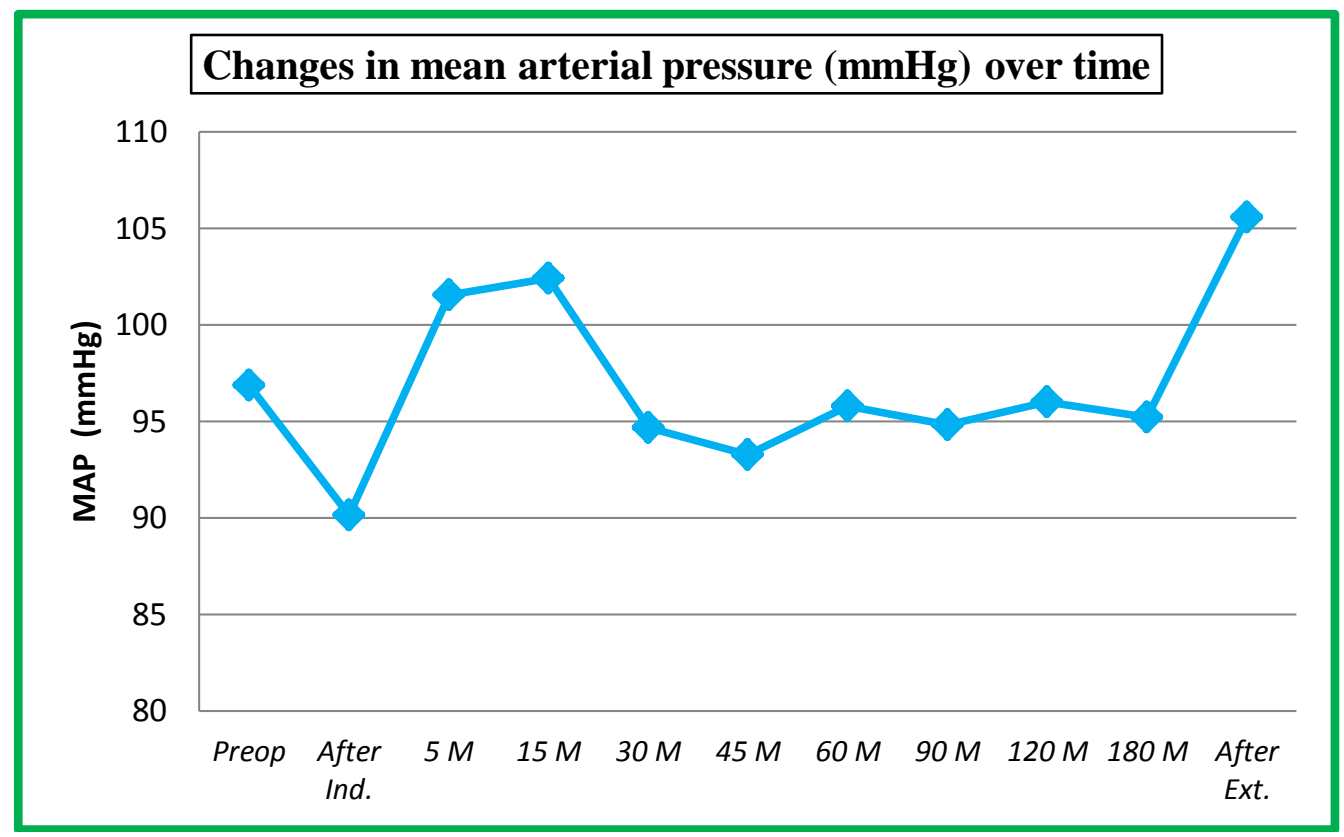

Figure 14:-Line chartshowing changes in Mean arterial pressure over time.

\section{Discussion :-}

100 patients undergoing elective laparoscopic surgery under GA were studied. On comparing the gender distribution, we found 67 (67\%) patients were female and 33(33\%) were male.

In our study patients above 18 years of age belonging to ASA I, II, III and IV were studied with majority of the patients belonging to age group $45-59$ years (29\%) with mean age of 43.1 years . In our study, $34 \%$ of patients i,e (17\% each) belonged to high risk group ( ASA III and IV) ..

In our study, we studied the effect of PNP on $\mathrm{pH}$ of arterial blood during the procedure and after deflation. We found that, there was significant $(\mathrm{p}<.001)$ decrease in $\mathrm{pH}$ after creation of PNP. The arterial $\mathrm{pH}$ decreased after PNP with minimum value of 7.21 at $60 \mathrm{~min}$. There was slight increase in $\mathrm{pH}$ (mean $\mathrm{pH} 7.32, \mathrm{p}<.001$ ) in postoperative period after deflation of pneumoperitoneum. Our findings correlated with the study conducted by Makwana DS et al ${ }^{9}$ who in their study found that, there was significant decrease in $\mathrm{pH}$ after creation of PNP.

In their study, arterial $\mathrm{pH}$ decreased from 7.37 to 7.22 at $120 \mathrm{~min}$ which was statistically significant. In study done by Tran DTT etal ${ }^{10}$, showed that $\mathrm{CO}_{2}$ insufflation lowered the $\mathrm{pH}$ to 7.31 from 7.40 which was statistically highly significant with $\mathrm{p}$ value $<.001$.GandaraVeta ${ }^{11}$ in their study observed that, Blood $\mathrm{pH}$ lowered significantly $(\mathrm{p}<.05)$ with pneumoperitoneum from its first determination, reaching its lowest level at the recovery-room arrival determination, after that a significant gradual increase was observed, with nearly normal values 90 min later. No correlation was found between these parameters and duration of procedures or total amount of $\mathrm{CO}_{2}$ used.

In our study we found that, there was increase in $\mathrm{PaCO}_{2}$ after creation of $\mathrm{CO}_{2}$ pneumoperitoneum . $\mathrm{PaCO}_{2}$ increase from pre-insufflation value of $35 \mathrm{mmHg}$ to a maximum value of $47 \mathrm{mmHg}$ at $180 \mathrm{~min}$. The change in $\mathrm{PaCO}_{2}$ was significant ( $\mathrm{p}<.001$ ) during first $90 \mathrm{~min}$ after insufflation and returned towards baseline in postoperative period. The changes in $\mathrm{PaCO}_{2}$ were non - significant at $120 \mathrm{~min}(\mathrm{p}=0.139)$ and $180 \mathrm{~min}(\mathrm{p}=0.164)$ which may be due to lesser number of cases $(\mathrm{n}=2)$ at $120 \mathrm{~min}$ and $180 \mathrm{~min}$. Our observation correlated with study conducted by Makwana DS etal ${ }^{9}$ who in their study observed significant increase in $\mathrm{PaCO}_{2}$ after $\mathrm{CO}_{2}$ insufflation. $\mathrm{PaCO}_{2}$ increased from baseline value of $36.28 \mathrm{mmHg}$ to $42.66 \mathrm{mmHg}$. $\mathrm{PaCO}_{2}$ remained on higher side during PNP and returned towards baseline after deflation (Mean postop $\mathrm{PaCO}_{2} 39.4 \mathrm{mmHg}$ ) .

Leighton TA et al. ${ }^{12}$ in their study 'Comparative cardiopulmonary effects of carbon dioxide versus helium pneumoperitoneum' found that Carbon dioxide absorption during $\mathrm{CO}_{2}$ pneumoperitoneum caused arterial $\mathrm{PaCO}_{2}$ to 
increase from $41.3 \pm 3.0$ to a maximum of $58.3 \pm 4.0 \mathrm{~mm} \mathrm{Hg}$, with $\mathrm{pH}$ descending from $7.46 \pm 0.02$ to a nadir of $7.31 \pm 0.02(\mathrm{p}<0.05)$.

In our study changes in $\mathrm{EtCO}_{2}$ corresponded to changes in $\mathrm{PaCO}_{2}$. There was statistically significant $(\mathrm{p}<.001$ ) increase in $\mathrm{EtCO}_{2}$ after creation of $\mathrm{CO}_{2} \mathrm{PNP}$. There was significant rise in $\mathrm{EtCO}_{2}$ after $\mathrm{CO}_{2} \mathrm{PNP}$ from $31.0 \mathrm{mmHg}$ pre insufflation to $35.0 \mathrm{mmHg}$ after $15 \mathrm{~min}$ of insufflation $(\mathrm{p}<.001)$ which was statistically significant. $\mathrm{EtCO}_{2}$ remained statistically higher with up to $90 \mathrm{~min}$ after insufflation with $\mathrm{p}<0.05$, thereafter there was decrease in $\mathrm{EtCO}_{2}$ after deflation. Our observation correlated with Makwana DS et al ${ }^{9}$ who in their study found that there was significant rise in $\mathrm{EtCO}$ after insufflation, maximum at 60 minutes and return to baseline after desufflation $(\mathrm{P}$ value $=$ 0.0036). You $\mathrm{SH}$ et al ${ }^{13}$ studied that $\mathrm{PaCO}_{2}$ and $\mathrm{EtCO} 2$ were significantly increased during $\mathrm{CO}_{2}$ insufflation compared with preinsufflation values in different kind of surgeries.

In our study, minute ventilation was increased to keep $\mathrm{EtCO}_{2}$ less than $45 \mathrm{mmHg}$. Increase in minute ventilation was statistically significant $(\mathrm{p}<.0001)$ with mean value $=5.028 \mathrm{~L} / \mathrm{min}$ to $8.33 \mathrm{~L} / \mathrm{min}$ at $180 \mathrm{~min}$. The increase in minute ventilation was necessary to limit increase in $\mathrm{EtCO}_{2}$ more than $45 \mathrm{mmHg}$ during the procedure, which correlates with changes observed by McMahon $\mathrm{AJ}$ et $\mathrm{al}^{14}$ in their study found that, despite an increase in minute ventilation from a mean (s.d.) of $5 \cdot 7( \pm 1 \cdot 4)$ to $6 \cdot 1( \pm 1 \cdot 2) \mathrm{L} / \mathrm{min}$, mean(S.D.) arterial carbon dioxide tension $(\mathrm{PaCO} 2)$ rose from $5 \cdot 3( \pm 0 \cdot 9)$ to $6 \cdot 0( \pm 0 \cdot 9) \mathrm{kPa}$ during laparoscopic cholecystectomy.

In our study there was significant decrease in bicarbonate levels during first $15 \mathrm{~min}$ after insufflations (preop mean value $=24.9,15 \mathrm{~min}$ mean value $=21.8 \mathrm{mEq} / \mathrm{L}$ ) with $\mathrm{p}<0.05$ after $15 \mathrm{~min}$. Bicarbonate levels remained on lower side during PNP but after initial $15 \mathrm{~min}$ the decrease in bicarbonate levels was not significant ( $>$.05). In our study, bicarbonate leves returned towards baseline after deflation of PNP. Our findings correlate with the study of GandaraVetal ${ }^{11}$ who in their study, observed significant $(\mathrm{p}<.001)$ decrease in bicarbonate levels after creation of PNP. They also observed increase in bicarbonate levels after deflation, with the bicarbonate levels returning towards baseline in recovery room after procedure. The cause of the metabolic acidosis however could not be elucidated in this study as several components of the metabolic profile necessary to fully characterize the metabolic acidosis like the lactate levels, electrolytes, albumin and other anions were not measured. However it has been postulated that the metabolic acidosis is secondary to organ hypo-perfusion during pneumoperitoneum

In our study, mean difference between $\mathrm{PaCO}_{2}$ - $\mathrm{EtCO} 2$ was statistically insignificant with $\mathrm{p}>0.05 . \mathrm{PaCO}_{2}$-EtCO2 gradient increased beyond $5 \mathrm{mmHg}$ after $60 \mathrm{~min}$ of insufflation which was suggestive of poor precision of $\mathrm{EtCO}_{2}$ in predicting $\mathrm{PaCO}_{2}$ after the increase in $\mathrm{PaCO}_{2}-\mathrm{EtCO}_{2}$ gradient beyond $5 \mathrm{mmHg}$ which correlates with the study conducted by McMahon AJ et al. ${ }^{14}$ on 'Ventilatory and blood gas changes during laparoscopic and open cholecystectomy' found that, despite an increase in minute ventilation from a mean(s.d.) of $5 \cdot 7( \pm 1 \cdot 4)$ to $6 \cdot 1( \pm 1 \cdot 2)$ $\mathrm{L} / \mathrm{min}$, mean(S.D.) arterial carbon dioxide tension $(\mathrm{PaCO} 2)$ rose from $5 \cdot 3( \pm 0 \cdot 9)$ to $6 \cdot 0( \pm 0 \cdot 9) \mathrm{kPa}$ during laparoscopic cholecystectomy. End-tidal carbon dioxide tension ( $\left.\mathrm{PE}^{\prime} \mathrm{CO} 2\right)$ had poor precision in predicting $\mathrm{PaCO} 2$ (95 per cent interval of agreement -0.61 to $1.93 \mathrm{kPa}$ ). Mean (S.D.) peak airway pressure increased from 17(4) to 23(4) $\mathrm{cmH} 2 \mathrm{O}$. The mean $\mathrm{PaCO}_{2}-\mathrm{EtCO}_{2}$ value did not change significantly. They concluded that, laparoscopic cholecystectomy requires a substantial but variable increase in minute ventilation to compensate for carbon dioxide absorption from the peritoneum.

In this study there was progressive widening of the $\mathrm{PaCO} 2-\mathrm{EtCO} 2$ gradient which however was found to be statistically insignificant ( $\mathrm{p}$ value $>0.05)$. A correlation between $\mathrm{PaCO} 2$ and $\mathrm{EtCO} 2(\mathrm{r}=0.92)$ was observed in this study. This is similar to findings of Nyarwayaet al ${ }^{15}$ and Baraka et al ${ }^{16}$ who also noted a correlation between the two. This implies that EtCO2 is still a reliable non-invasive surrogate for monitoring $\mathrm{PaCO} 2$ during laparoscopy. However in a recent study by Ozyuvacieta ${ }^{17}$ where transcutaneous, arterial and end-tidal measurements of carbon dioxide were compared during pneumoperitoneum they noted that $\mathrm{EtCO} 2$ was significantly lower than $\mathrm{PaCO} 2$ whilst transcutaneous carbon dioxide (TcPCO2) was much closer to $\mathrm{PaCO} 2$ concluding that $\mathrm{TcPCO} 2$ was a valid and practical measurement compared with $\mathrm{EtCO} 2$ but both could be used to estimate $\mathrm{PaCO} 2$.

In our study, on comparing changes in heart rate over a period of time with baseline hear trate (mean value $=78.5$ beats/min) we found that there was significant $(\mathrm{p}<.001)$ increase in heart rate after induction of anesthesia (mean value $=107.8$ beats $/ \mathrm{min})$ and pneumoperitonium which remained significantly $(\mathrm{p}<.001)$ raised up to 60min of procedure. Also we found that there was significant $(\mathrm{p}<.001)$ rise in heart rate after extubation. Pre-induction maximum rise in hear trate was $95 \mathrm{bpm}$, after induction maximum rise was $125 \mathrm{bpm}$ and following 
extubationmaximum rise was $103 \mathrm{bpm}$. Our observation correlates with the study by Bandhari D et al ${ }^{18}$, in their study mean rise of varied from 76.8 to $111.14 \mathrm{bpm}$, the difference in values is due to difference in sample size of study.

In our study, on comparing changes in systolic blood pressure of patients during pneumoperitoneum with baseline systolic blood pressure (mean value $=124.2 \mathrm{mmHg}$ ), we found that, there was significant fall $(\mathrm{p}<.001)$ in systolic blood pressure after induction of anesthesia (mean value $=118.0 \mathrm{mmHg}$ ), which was followed by increase in systolic blood pressure after $\mathrm{CO}_{2}$ pneumoperitoneum. The increase in systolic blood pressure was maximum at 5 min with mean value of $131 \mathrm{mmHg}(\mathrm{p}<.001)$. The changes in systolic blood pressure gradually returned towards baseline after $15 \mathrm{~min}$. we also noted significant $(\mathrm{p}<.001)$ increase in systolic blood pressure after extubation. The changes in blood pressure can be attributed to various factors like intra-abdominal pressure, patient position, ASA status of patient and remedication received by the patient.

Diastolic blood pressure (baseline mean $=83.6 \mathrm{mmHg}$ in preop) also decreased after induction of anesthesia (mean value $=76.7 \mathrm{mmHg})$. We observed significant $(\mathrm{p}<.001)$ increase in diastolic blood pressure after PNP upto $15 \mathrm{~min}$ (mean value $=88.8 \mathrm{mmHg}$ at $15 \mathrm{~min}$ ) after which blood pressure returned towards baseline. We also noted significant rise $(\mathrm{p}<.001)$ at extubation in response to deflation and extubation of trachea. Our observation correlated with the study conducted byBhandari D etal ${ }^{18}$, they observed that in spite of maintaining normocapnia and keeping intraabdominal pressure below $14 \mathrm{mmHg}$ significant rise in heart rate, systolic blood pressure, diastolic blood pressure and mean arterial pressure was noticed. Rise in systolic, diastolic and mean arterial pressure was more than $20 \%$ from the baseline.

In our study changes in mean arterial pressure (MAP) were studied throughout the procedure which corresponded to changes in systolic and diastolic blood pressure. There was significant decrease in MAP (baseline MAP=96.9 $\mathrm{mmHg}$ ) after induction (mean MAP $=90.2 \mathrm{mmHg}, \mathrm{p}<.001$ ), which was followed by significant rise in MAP up to first $15 \mathrm{~min}$ (mean $=102.4 \mathrm{mmHg}$ ). MAP returned towards baseline after $15 \mathrm{~min}$. we found there was no significant

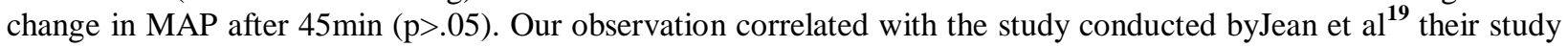
confirms that peritoneal carbon dioxide insufflation to an IAP of $14 \mathrm{mmHg}$ produces significant hemodynamic change, and pneumoperitonium result in increase in mean arterial pressure (MAP). Similar findings were reported by Bhandari Detal ${ }^{18}$, Das $\mathrm{M} \mathrm{etal}^{20}$ and Malek $\mathrm{J} \mathrm{etal}^{21}$.

\section{Conclusion:-}

In our study, we concluded that laparoscopic surgery with $\mathrm{Co} 2$ pneumoperitonium lead to significant acidosis, increase in $\mathrm{PaCo} 2$ and decrease in bicarbonate levels, as well as there is significant change in hemodynamic parameters. These changes were well tolerated by patients by optimizing patients prior to surgery. By increasing minute ventilation during procedure large increase in $\mathrm{PaCo} 2$ can be minimized. A correlation was observed between the $\mathrm{PaCo} 2$ and $\mathrm{EtCo} 2$ throughout the duration of the insufflation making EtCo 2 a reliable monitor of Co2 output during laparoscopy. In our study, we also noted significant rise in heart rate, blood pressure and MAP but these changes were well tolerated by patients belonging to different ASA categories. In our study high risk patients (ASA II, III, and IV) were optimized before surgery and the changes induced during procedure were well compensated. In our study, we also noted large shifts in metabolic parameters among patients undergoing prolonged surgery but due to lesser number of cases in our study there was no statistical significance which needs further study with adequate sample size .

\section{Bibliography:-}

1. Wellwood J, Sculpher MJ, Stoker D, Nicholls GJ, Geddes C, Whitehead A et al. Randomised controlled trial of laparoscopic versus open mesh repair for inguinal hernia: outcome and cost. BMJ 1998;317:103-110.

2. Zacks SL, Sandler RS, Rutledge R, Brown RS Jr. A population based cohort study comparing laparoscopic cholecystectomy and open cholecystectomy. Am J Gastroenterol2002; 97:334-340. Anaesthesiol Scand. 1996; 40: 160-166.

3. Tan PL, Lee TL, Tweed WA. Carbon dioxide absorption and gas exchange during pelvic laparoscopy. Can J Anaesth. 1992; 39: 677-681.

4. Sharma KC, Brandstetter RD, Brensilver JM, Jung LD. Cardiopulmonary physiology and pathophysiology as a consequence of laparoscopic surgery. Chest. 1996; 110: 810-815. 
5. Hong JY, Kim WO, Kil HK. Detection of subclinical CO2 embolism by transesophageal echocardiography during laparoscopic radical prostatectomy. Urology. 2010; 75: 581-584.

6. Gutt CN, Oniu T, Mehrabi A, Schemmer P, Kashfi A, Kraus T, Büchler MW. Circulatory and respiratory complications of carbon dioxide insufflation. Dig Surg. 2004; 21: 95-105.

7. Bonjer HJ, Hazebroek EJ, Kazemier G, Giuffrida MC, Meijer WS, Lange JF. Open versus closed establishment of pneumoperitoneum in laparoscopic surgery. Br J Surg. 1997; 84: 599-602.

8. O'Leary E, Hubbard K, Tormey W, Cunningham AJ. Laparoscopic cholecystectomy: haemodynamic and neuroendocrine responses after pneumoperitoneum and changes in position. Br J Anaesth. 1996; 76: 640-644 .

9. Makwana DS, Patil PN, Cercetta CS. A comparison of EtCO2 and $\mathrm{PaCO} 2$ in laparoscopic surgery during general anesthesia. GCSMC J Med Sci. 2014;3:12-5.

10. Tran DTT, Badner NH, Nicolaou G, Sischek W. Arterial pCO changes during thoracoscopic surgery with $\mathrm{CO}$ insufflation and one lung ventilation. HSR proceedings in Intensive Care and Cardiovascular Anesthesia 2010;2:191-7.

11. Gandara, V., De Vega, D. S., Escriu, N. \&Zorrilla, I. G. Acid-base balance alterations inlaparoscopic cholecystectomy. Surgical Endoscopy 1997; 11: 707-710.

12. Leighton TA, Liu SY, Bongard FS. Comparative cardiopulmonary effects of carbon dioxide versus helium pneumoperitoneum. Surgery. 1993 May;113(5):527-31.

13. You SH, Kim JB, Jung HJ, Ahn MJ, Kim JS, Park SS, Mun JH. Comparison of Changes in Arterial Blood Gases during Endoscopic Thyroidectomy, Laparoscopic Cholecystectomy and Gynecologic Laparoscopic Surgery. Korean J Anesthesiol.2002 Apr; 42(4): 431-7.

14. McMahon AJ, Baxter JN, Kenny G, O'Dwyer PJ. Ventilatory and blood gas changes during laparoscopic and open cholecystectomy. British Journal of Surgery. 1993 Oct;80(10):1252-4.

15. NyarwayaJB, MazoitJX and SamiiK. Are pulse oximetry and end-tidalcarbon dioxide tension monitoring reliable during laparoscopic surgery? Anaesthesia 1994; 49: 775-778.

16. BarakaA. et al. End-tidal carbon dioxide tension during laparoscopic cholecystectomy.Anaesthesia 2007; 49: 304-306.

17. Ozyuvaci, E. et al. Comparison of transcutaneous, arterial and end-tidal measurements of carbon dioxide during laparoscopic cholecystectomy in patients with chronicobstructive pulmonary disease. The Journal of International Medical Research 2012; 40: 1982-1987.

18. Bhandari D, Tidke S, Sharma V, Dongre H, Garg D, Dhande P. Hemodynamic changes associated with laparoscopic cholecystectomy: effect of oral clonidine premedication. IOSR Journal of Pharmacy. 2012;2(4):72-7.

19. Joris JL, Chiche JD, Canivet JLM, Jacquet NJ, Legros JJY, Lamy ML. Hemodynamic changes induced by laparoscopy and their endocrine correlates: effects of clonidine. JACC 1998;32(5):1389-96.

20. Das M, Ray M, Mukherjee G. Haemodynamic changes during laparoscopiccholccystectomy: Effect of clonidine premedication. Indian Journal of Anaesthesia. 2007 May;51(3):205.

21. Malek J, Knor J, Kurzova A, Lopourova M. Adverse hemodynamic changes during laparoscopic cholecystectomy and their possible suppression with clonidine premedication. Comparison with intravenous and intramuscular premedication. Rozhledy v chirurgii: mesicnikCeskoslovenskechirurgickespolecnosti. 1999 Jun;78(6):286-91. 